\title{
Vascular repair is vulnerable to renal regeneration in early stage of diabetic nephropathy
}

Recent studies on vascular homeostasis in type 2 diabetic patients associated with altered serum creatinine concentration or presence of microalbuminuria have revealed an impaired mechanism of vascular repair, namely defective angiogenic factors, such as VEGF receptor 1 , angiopoietin-1 in conjunction with abnormally elevated levels of anti-angiogenic factors such as VEGF receptor 2 and angiopoietin-2 [1]. Such impaired vascular repair explains: 1 ) reduction in renal perfusion observed in these patients, 2) unresponsiveness to vasodilators that are usually initiated at the late stage of diabetic nephropathy, resulting in therapeutic failure and progressive impairment of renal function towards end-stage renal disease. Under common practices, type 2 diabetic patients have generally been underestimated at the early stage (normal serum creatinine and normo-albuminuria), and usually been left unattended.

To classify this specific issue further, we have recently demonstrated that 18 diabetic patients (10 males and 8 females, age: $45 \pm 13$ years ranging $25-71$ years) associated with normal serum creatinine level and normo-albuminuria have impaired actual creatinine clearance (chronic kidney disease stage 1 and 2) (see Table 1).

Evidence of diabetic nephropathy is reflected by an abnormally elevated fractional excretion of magnesium - an index that has previously been demonstrated to directly correlate with the presence of tubulointerstitial fibrosis [2, 3]. Furthermore, the mechanism of vascular repair in this early stage is not significantly different from the normal controls, and thus appears to be adequately functional. Theoretically, normal angiogenic factors observed would allow the process of activating vascular repair through the classical pathway (VEGF $\rightarrow$ VEGFR1) by which it might induce coupling of endothelial nitric oxide synthese, and eventually enhance nitric oxide production from the arginine substrate $[4,5]$.

The above view is further supported by clinical trial with multi-drug vasodilators such as enalapril 5$10 \mathrm{mg} / \mathrm{D}$, angiotensin receptor blocker (Micardis) 40$80 \mathrm{mg} / \mathrm{D}$, in addition to the correction of metabolic disorders, which has indeed increased renal plasma flow and peritubular capillary flow in conjunction with the increase in actual creatinine clearance [6, 7]. The reduction in fractional excretion of magnesium following treatment implies that there is likely reduction in the degree of tubulointerstitial fibrosis, or it reflects renal regeneration.

In conclusion, treatment of diabetic nephropathy at the early stage under the environment favorable for renal regeneration would effectively restore renal perfusion and enhance renal function.

This study was supported by Thailand Research Fund, National Research Council Fund of Thailand and Royal Society of Thailand. The authors declare no relevant financial interests.

Table 1. Enhanced renal perfusion and function in the early stage of type 2 diabetic patients (normal serum creatinine and normo-albuminuria).

\begin{tabular}{|c|c|c|c|c|}
\hline & Pre-treatment & P-value & Post-treatment & Normal \\
\hline \multicolumn{5}{|l|}{ Hemodynamics } \\
\hline Renal plasma flow (mL/min/1.73m²) & $470 \pm 57$ & $<0.05$ & $539 \pm 45$ & $605 \pm 39$ \\
\hline Glomerular filtration rate $\left(\mathrm{mL} / \mathrm{min} / 1.73 \mathrm{~m}^{2}\right)$ & $85 \pm 25$ & $<0.05$ & $106 \pm 30$ & $119 \underline{+15}$ \\
\hline Peritubular capillary flow (mL/min/1.73m²) & $382 \pm 62$ & $<0.05$ & $433 \pm 42$ & $485 \pm 39$ \\
\hline Serum creatinine (mg/dL) & $0.9 \pm 0.1$ & NS & $0.8 \pm 0.2$ & $\leq 1$ \\
\hline Creatinine clearance $\left(\mathrm{mL} / \mathrm{min} / 1.73 \mathrm{~m}^{2}\right)$ & $94 \pm 22$ & $<0.01$ & $113 \pm 23$ & 120 \\
\hline Fractional excretion of Mg (FE Mg \%) & $3.4 \pm 1.5$ & $<0.05$ & $2.5 \pm 0.1$ & $1.6 \pm 0.6$ \\
\hline Microalbumin/creatinine ratio ( $\mu \mathrm{g} / \mathrm{mg})$ & $14 \pm 6$ & $<0.05$ & $11 \pm 4$ & $<30$ \\
\hline
\end{tabular}

NS= not significant. 
Narisa Futrakul, Prasit Futrakul

Faculty of Medicine, Chulalongkorn University, Bangkok 10330, Thailand. E-mail: fmednft@md. chula.ac.th

\section{References}

1. Futrakul P, Butthep P, Futrakul P. Altered vascular homeostasis in type 2 diabetic nephropathy. Ren Fail. 2009; 31:207-10.

2. Futrakul P, Yenrudi S, Futrakul N, Sensirivatana R, Kingwatanakul P, Jungthirapanich J, et al. Tubular function and tubulointerstitial disease. Am J Kidney Dis. 1999; 33:886-91.

3. Futrakul N, Sila-asna M, Futrakul P. Therapeutic strategy towards renal restoration in chronic kidney disease. Asian Biomed. 2007; 1:33-44.

4. Futrakul N, Futrakul P. Improved vascular repair is relevant to enhanced renal function with vasodilators in early stage of chronic kidney disease. Asian Biomed. 2010;4:153-7.

5. Futrakul N, Futrakul P. Vascular homeostasis and disease progression in chronic kidney disease. Asian Biomed. 2009; 3:589-94.

6. Futrakul N, Butthep P, Futrakul P, Sitprija V. Improvement of renal function in type 2 diabetic nephropathy. Ren Fail. 2007; 29:155-158.

7. Ritt M, Ott C, Raff U, Schneider MP, Schuster I, Hilgers $\mathrm{KF}$, et al. Renal vascular endothelial function in hypertensive patients with type 2 diabetes mellitus. Am J Kidney Dis. 2009; 53:281-9. 